Published June 2018

\title{
Sistem Pengamatan Hilal ISRN UHAMKA
}

\author{
Adi Damanhuri \\ The Islamic Science Research Network (ISRN) \\ Universitas Muhammadiyah Prof. DR. HAMKA \\ Email: adidamanhuri@uhamka.ac.id
}

\begin{tabular}{|c|c|}
\hline Abstrak & \\
\hline $\begin{array}{l}\text { Kemajuan ilmu pengetahuan dan teknologi memberi } \\
\text { dampak yang luar biasa diberbagai sendi kehidupan. } \\
\text { Indonesia yang mayoritasnya beragama Islam, sebagian } \\
\text { besar masyarakatnya masih melakukan pengamatan hilal } \\
\text { untuk memastikan masuknya awal bulan baru hijriah. } \\
\text { Penngamatan yang dilakukan bermacam-macam, dari yang } \\
\text { sederhana hanya menggunakan mata telanjang hingga } \\
\text { pengamatan yang sudah menggunakan berbagai teknologi } \\
\text { penunjang. The Islamic Science Research Network (ISRN) } \\
\text { Universitas Muhammadiyah Prof. DR. HAMKA teah } \\
\text { membangun sistem pengamatan hilal yang menggunakan } \\
\text { teknologi terkini yang terdiri dari teleskop William Optic } \\
\text { Zenith Star 71ED, kamera CCD Skyris 274M, dudukan } \\
\text { teleskop tipe iOptron CEM60, dan filter Baader 685nm. } \\
\text { Sebagai instrumen pembantu, sistem teleskop ditambah } \\
\text { dengan baffle untuk menapis kuatnya cahaya Matahari pada } \\
\text { saat pengamatan. } \\
\text { Keyword: Teleskop, Hilal. }\end{array}$ & $\begin{array}{c}\text { Received: } \\
15 \text { Februari } 2018 \\
\text { Revised: } \\
13 \text { Maret } 2018 \\
\text { Accepted: } \\
\text { 19 Mei 2018 }\end{array}$ \\
\hline
\end{tabular}

\section{A. Pendahuluan}

Menurut data survey Badan

Pusat Statistik yang dirilis tahun $2010^{1}$ menunjukkan bahwa $87,18 \%$ masyarakat Indonesia memeluk agama Islam. Berdasarkan data tersebut, maka

1 Badan Pusat Statistik, Hasil Sensus Penduduk 2010: Kewarganegaraan, Suku Bangsa, Agama, dan Bahasa Sehari-Hari Penduduk Indonesia, (Jakarta: Badan Pusat Statistik, 2010), h. 10. umat Islam di Indonesia merupakan mayoritas, dan segala bentuk kegiatan peribadatan khsuusnya peribadatan yang bersifat massal dari umat Islam melibatkan banyak pihak, termasuk persiapan dan pelaksanaannya. Penentuan awal bulan hijriah merupakan suatu hal yang menarik perhatian masyarakat, karena tidak 
AL-MARSHAD: JURNAL ASTRONOMI ISLAM DAN ILMU-ILMU BERKAITAN

ISSN 2442-5729 (print) || ISSN 2598-2559 (online), http://jurnal.umsu.ac.id/index.php/almarshad DOI: https://doi.org/10.30596/jam.v4i1.1931

Published June 2018

hanya memuat kaidah-kaidah keagamaan namun sarat dengan kaidah ilmu pengetahuan khususnya Astronomi.

Di masyarakat Indonesia, secara garis besar ada dua pandangan untuk menentukan awal bulan hijriah, yaitu melalui perhitungan yang akrab dengan istilah hisab, dan dengan pengamatan hilal pada saat Matahari terbenam di tanggal 29 bulan hijriah berjalan, yang dikenal dengan istilah rukyat. Diantara 12 bulan hijriah, setidaknya Ramadan, Syawal, dan Zulhijjah merupakan bulan hijriah yang menyita perhatian masyarakat ${ }^{2}$, karena pada bulan-bulan tersebut terdapat kegiatan ibadah umat Islam yang bersifat massal, yaitu ibadah puasa di bulan ramadhan, hari raya idul fitri di awal syawal, dan ibadah haji dan hari raya idul adha di bulan zulhijjah. Dalam sejarah, hilal telah menjadi obyek pengamatan sejak zaman Babilonia Baru tepatnya antara tahun 5658 SM hingga $74 \mathrm{SM}^{3}$. Menurut

2 Adi Damanhuri, Desain Sistem Pengamatan Sabit Bulan di Siang Hari, (Jakarta: SEMNASTEK, 2015), h.3.

3 Doggett, L.E., Schaeffer, B.E. Lunar Crescent Visibility (ICARUS, 1994), h. $388-403$.
Herdiwijaya $^{4}$, berdasarkan kemajuan ilmu pengetahuan dan teknologi maka pengamatan sabit Bulan dapat dilakukan pada siang hari (daylight observation). Pengamatan yang dimaksud tentu menggunakan instrumen-instrumen yang berbasis teknologi, seperti kamera digital dengan sistem kerja CCD, dudukan teleskop yang mampu mengikuti gerak semu benda-benda langit khususnya Bulan, teleskop, dan instrumen tambahan seperti seperti filter untuk mempersempit panjang gelombang, dan baffle untuk menapis cahaya yang berasal dari Matahari dan sumber lainnya agar tidak mengganggu photon yang berasal dari hilal.

Pengamatan hilal menggunakan berbagai teknologi dan kamera digital kini tidak hanya untuk menentukan awal bulan hijriah, tetapi juga menjadi ajang pemecahan rekor untuk jarak

4 Dhani Herdiwijaya, Mitra Djamal, M., Gunawan, Mexsida, Z.A., Deni Mandey, Wijaya,R.R. Developing Telescope Baffle For Increasing Contrast Of The Very Young Lunar Crescent Visibility. ( Bandung: Proceedings of the Thrid International Conference on Mathematical and Natural Sciense.2010), h.1214-1220. 
elongasi terdekat ${ }^{5}$. Seperti yang telah dilakukan oleh Thiery Legault ${ }^{6}$. ISRN UHAMKA mengembangkan sistem pengamatan hilal lebih kepada fungsi edukasi keilmuan astronomi dan partisipasi dalam kontestasi pemecahan rekor. Sistem pengamatan hilal yang dmiliki ISRN UHAMKA juga menggunakan metodologi astsronomy proper atau pengamatan dan komputasi, detektor digunakan adalah kamera digital berupa CCD yang mampu menangkap sinyal photon yang berasal dari hilal, dan data pengamatan tersebut dapat disimpan. Selain itu, untuk keperluan pengamatan hilal, ISRN UHAMKA mengembangkan aplikasi kontrol kamera CCD khusus yang fungsi dan kerjanya sudah memuat fungsi peningkatan kontras agar hilal dapat terlihat dengan jelas dibalik kuatnya cahaya Matahari.

\section{B. Latar Belakang}

Sistem pengamatan hilal ISRN UHAMKA dibangun didasari oleh beberapa pertimbangan utama diantaranya: (1) Sebagai tugas pokok ISRN UHAMKA yaitu melakukan

5 Adi Damanhuri, Desain Sistem Pengamatan Sabit Bulan di Siang Hari, (Jakarta: SEMNASTEK, 2015), h.2.

6 Ibid, h.8. kajian-kajian sains Islam, (2) Upaya pengembangan keahlian Astronomi di lingkungan Universitas Muhammadiyah Prof DR HAMKA khususnya dan di lingkungan Muhammadiyah pada umumnya, khususnya untuk keahlian pengoperasian instrumen-instrumen pengamatan astronomi, dan (3) Bentuk partisipasi ISRN UHAMKA dalam kontestasi [emecahan rekor pengamatan hilal dengan jarak elongasi minimal.

\section{Tinjauan Pustaka}

Saat ini sebagian besar pengamatan hilal dilakukan tanpa menggunakan teleskop ${ }^{7}$, maka pengamatan sabit Bulan terlebih dilakukan pada siang hari harus menggunakan teleskop. Instrumen untuk pengamatan sabit Bulan secara umum mencakup kolektor, analisator dan detektor. Secara detail peralatan yang digunakan seperti dudukan (mounting), tripod/monopod, Optical Tube Assembly (OTA), selongsong penghalang (baffle), rumah teleskop,

7 Dhani Herdiwijaya, Mitra Djamal, M., Gunawan, Mexsida, Z.A., Deni Mandey, Wijaya,R.R. Developing Telescope Baffle For Increasing Contrast Of The Very Young Lunar Crescent Visibility. ( Bandung: Proceedings of the Thrid International Conference on Mathematical and Natural Sciense.2010), h. 11215 . 
komputer atau laptop. Selain itu juga dibutuhkan perangkat lunak untuk kontrol teleskop dan pengolahan gambar secara real-time dalam sistem pengamatan sabit Bulan. Khusus untuk perangkat lunak yang digunakan penulis menerapkan konsep sederhana dan low cost atau gratis tersedia di internet. Instrumen yang penulis hadirkan juga harus memperhatikan karakteristik pengamatan sabit Bulan yang dilakukan pada siang hari.

\section{Tujuan Penelitian}

Makalah ini disusun sebagai bentuk nyata kegiatan ilmiah, dengan mendokumentasikan melalui makalah setiap detail dari sistem pengamatan hilal ISRN UHAMKA semoga dapat menjadi salah satu rujukan yang mudah diakses oleh sebanyak mungkin masyarakat yang memiliki keinginan untuk melakukan pengamatan hilal yang menggunakan teknologi. Terlebih, sebagian besar pengamatan hilal di Indonesia masih bersifat manual.

\section{E. Pembahasan}

Sistem pengamatan hilal ISRN UHAMKA terdiri dari beberapa instrumen, diantaranya seperti pada tabel 1.

Tabel 1. Daftar Instrumen Sistem Pengamatan Hilal ISRN UHAMKA

\begin{tabular}{|c|c|c|c|}
\hline No & Instrumen & Fungsi & Tipe \\
\hline 1 & Teleskop & $\begin{array}{l}\text { Sebagai kolektor sumber cahaya dari } \\
\text { objek yang diamati }\end{array}$ & $\begin{array}{l}\text { William Optic Zenith } \\
\text { Star 71ED }\end{array}$ \\
\hline 2 & Filter & $\begin{array}{l}\text { Sebagai penapis panjang gelombang } \\
\text { selain infra merah yang masuk ke } \\
\text { detector }\end{array}$ & $\begin{array}{l}\text { Baader IR pass filter } \\
685 \mathrm{~nm}\end{array}$ \\
\hline 3. & Detektor & $\begin{array}{l}\text { Instrumen penangkap sinyal atau } \\
\text { sumber cahaya dari objek yang } \\
\text { diamati }\end{array}$ & $\begin{array}{lr}\text { Kamera } & \text { CCD } \\
\text { Celestron } & \text { Skyris } \\
274 \mathrm{M} & \\
\end{array}$ \\
\hline 4. & $\begin{array}{l}\text { Dudukan } \\
\text { teleskop }\end{array}$ & 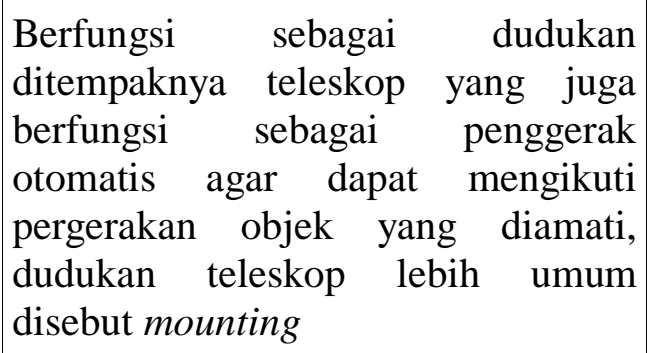 & Ioptron CEM60 \\
\hline 5. & $\begin{array}{l}\text { Penapis cahaya } \\
\text { (baffle) }\end{array}$ & $\begin{array}{l}\text { Berfungsi untuk menapis cahaya } \\
\text { Matahari yang masuk ke lensa } \\
\text { teleskop yang mengganggu kontras }\end{array}$ & Dibuat sendiri \\
\hline
\end{tabular}


AL-MARSHAD: JURNAL ASTRONOMI ISLAM DAN ILMU-ILMU BERKAITAN

ISSN 2442-5729 (print) || ISSN 2598-2559 (online), http://jurnal.umsu.ac.id/index.php/almarshad DOI: https://doi.org/10.30596/jam.v4i1.1931

Published June 2018

\begin{tabular}{|c|c|c|c|}
\hline No & Instrumen & Fungsi & Tipe \\
\hline & & cahaya hilal & \\
\hline 6. & $\begin{array}{l}\text { Perangkat } \\
\text { lunak kontrol } \\
\text { kamera }\end{array}$ & $\begin{array}{l}\text { Berfungsi agar fungsi detektor sudah } \\
\text { melakukan pengambilan data, } \\
\text { penyimpanan, dan modifikasi citra } \\
\text { agar kontras hilal meningkat }\end{array}$ & $\begin{array}{l}\text { Kontrol Kamera } \\
\text { ISRN UHAMK }\end{array}$ \\
\hline
\end{tabular}

\section{Teleskop}

Teleskop yang digunakan ISRN UHAMKA tipe William Optic Zenith Star 71 ED, yang memiliki diameter lensa $71 \mathrm{~mm}$ dan fokus rasio sebesar f/5.9. karakteristik detail teleskop William Optic ZS71ED seperti pada gambar 1 dan tabel 2.

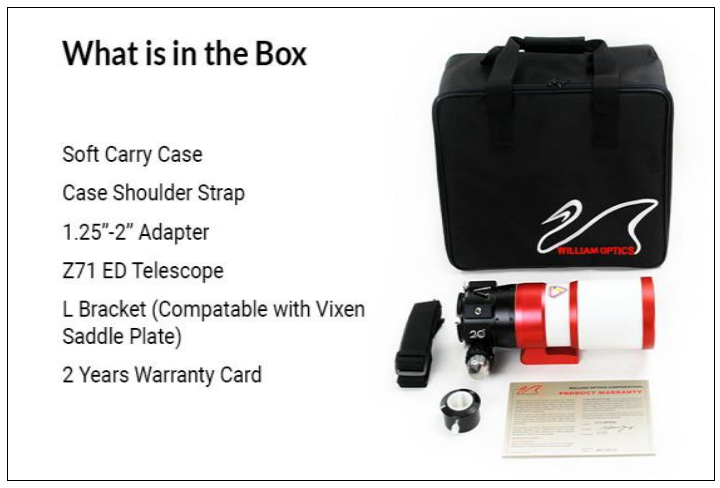

Gambar 1: William Optic Zenith Star $71 E D$ sumber: William Optic

Adapun detail teknins dari William Optic Zenith Star 71ED seperti pada gambar 2 . of. A-Z7IA-VP20A Back Focus

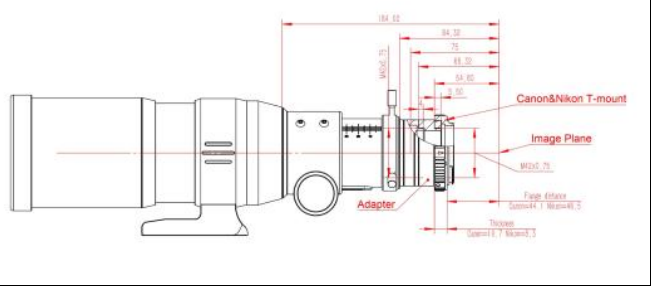

Gambar 2: Karakteristik Detail William Optic ZS71ED Sumber: William Optic

Tabel 2. Karakteristik William Optic Zenith Star 71ED ${ }^{8}$

\begin{tabular}{|l|l|}
\hline Bukaan lensa & $71 \mathrm{~mm}$ \\
\hline Rasio titik pusat & $\mathrm{F} / 5.9$ \\
\hline Panjang fokus & $418 \mathrm{~mm}$ \\
\hline $\begin{array}{l}\text { Tipe lensa } \\
\text { objektif }\end{array}$ & $\begin{array}{l}\text { ED Doublet, Air } \\
\text { Spaced, Fully Multy- } \\
\text { Coated, SMC coating }\end{array}$ \\
\hline Resolting power & 1.58 ' \\
\hline Batas magnitudo & 11 \\
\hline \{enutup lensa & Dapat digeser \\
\hline Focuser & $50.8 \quad$ mm (2”) Rack \\
\hline
\end{tabular}

8 http://williamoptics.com/20thedition/zenithstar-71-doublet-ed, diakses pada 15 Mei 2018, Pkl. 07:13:23 (UT+7) 


\begin{tabular}{|c|c|}
\hline \multicolumn{2}{|c|}{$\begin{array}{r}\text { AL-MARSHAD: JURNAL ASTRONOMI } \\
\text { ISSN 2442-5729 (print) || ISSN 2598-2559 (online } \\
\text { DOI: https://doi.org/1 } \\
\text { Published }\end{array}$} \\
\hline & 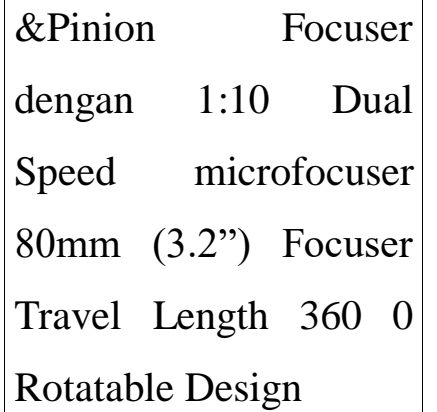 \\
\hline Diamter tabung & $93 \mathrm{~mm}$ \\
\hline Panjang tabung & $310 \mathrm{~mm}$ \\
\hline Tipe dudukan & Integrated L bracket \\
\hline Berat & $2.7 \mathrm{Kg}$ \\
\hline
\end{tabular}

\section{Filter}

Pengamatan hilal mengalami kendala, yaitu rendahnya kontras anara hilal dengan latar depannya berupa atmosfer yang menghamburkan cahaya Matahari dengan berbagai panjang geombang. Untuk mempersempit panjang gelombang yang masuk ke teleskop dan detektor, maka digunakan filter. ISRN UHAMKA menggunakan pass-filter infra-merah, artinya semua panjang gelombang yang masuk ke teleskop dan detektor ditapis, sedangkan panjang gelombang infra merah diteruskan. Filter infra merah yang digunakan oleh ISRN UHAMKA adalah Baader IR pass-filter $685 \mathrm{~nm}$, seperti terlihat pada gambar 3 .

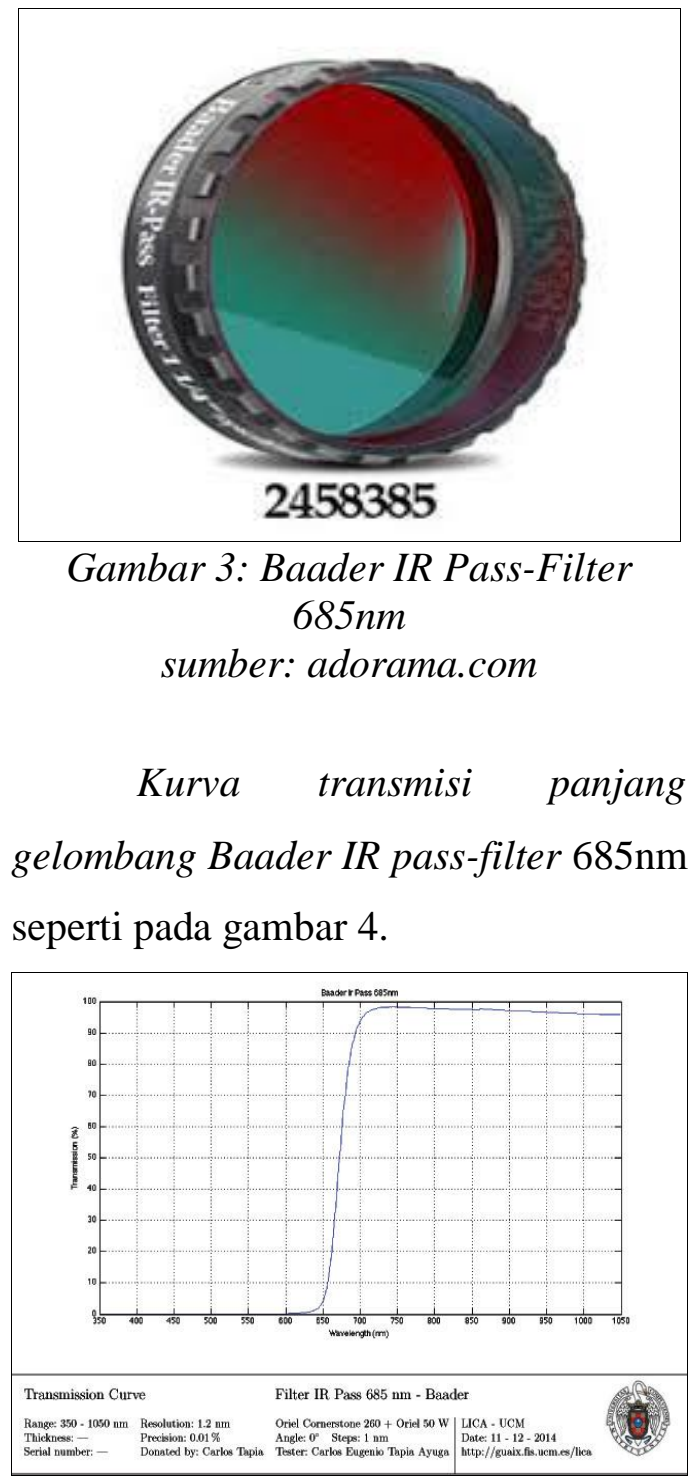

Gambar 4: Kurva Transmisi Baader IR pass-filter $685 \mathrm{~nm}$

sumber: http://guaix.fis.ucm.es/lica

\section{Detektor}

Detektor yang digunakan harus disesuaikan konfigurasinya dengan karakteristik dari teleskop. Konfigurasi antara karakteristik detektor dan krakteristik teleskop diharapkan menghasilkan bayangan objek yang 
AL-MARSHAD: JURNAL ASTRONOMI ISLAM DAN ILMU-ILMU BERKAITAN

ISSN 2442-5729 (print) || ISSN 2598-2559 (online), http://jurnal.umsu.ac.id/index.php/almarshad DOI: https://doi.org/10.30596/jam.v4i1.1931

Published June 2018

diamati proporsional. Jika bayangan terlalu kecil atau terlalu besar, maka pengamatan akan sangat sulit dilakukan karena akan menghasilkan data dan citra yang tidak baik. Khusus untuk pengamatan hilal, sebaiknya bayangan Bula menempati sekitar 50\% hingga $80 \%$ dari medan detektor agar bayangan $^{9}$ yang jatuh ke detektor proporsional untuk dilakuan pengolah dan peningkatan kontras. Mempertimbangkan konfigurasi tersbut, karena teleskop yang digunakan oleh ISRN UHAMKA adalah William Optic ZS71ED, maka ISRN UHAMKA menggunakan detektor kamera CCD Celestron 274M. Tipe kamera ini adalah kamera monokrom, artinya setiap intensitas pikselnya merentanng antara 0 hingga 256 atau dikenal dengan skala keabu-abuan (greyscale), dimana 0 mengindikasikan skala kehitaman sedangkan 256 menunjukkan skala putih. Seperti terlihat pada gambar 5 .

\begin{tabular}{|lccccc|}
\hline \multicolumn{7}{|c|}{ Shades of grey } \\
\hline \begin{tabular}{|llllll|}
\hline Black & 1 & 1 & & White \\
\hline 0 & 50 & 100 & 150 & 200 & 255 \\
\hline
\end{tabular}
\end{tabular}

9 Adi Damanhuri, Desain Sistem Pengamatan Sabit Bulan di Siang Hari, (Jakarta: SEMNASTEK, 2015), h.10.
Gambar 5: Skala keabu-abun (grayscale) sumber: https://hacktilldawn.com

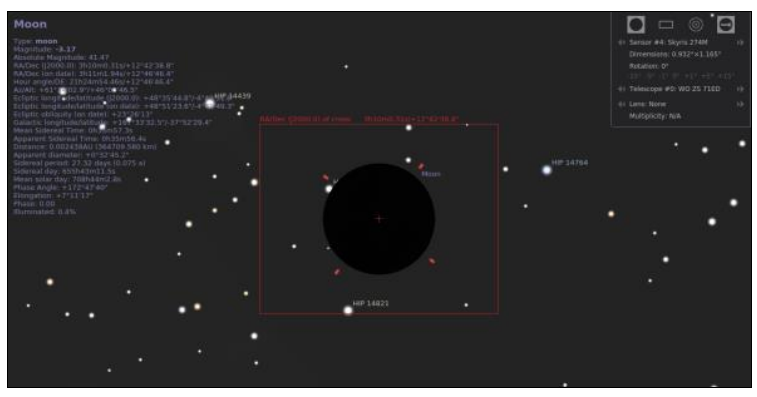

Gambar 6: Simulasi konfigurasi antara teleskop WO ZS71ED dan Kamera CCD Celestron Skyris 274M

Konfigurasi antara teleskop William Optic ZS71ED dan kamera CCD Skyris 274M, dapat disimulasikan menggunakan aplikasi Stellarium. Dari simulasi terlihat medan pandang yang terlihat pada sensor detektor cukup proporsional, seperti pada gambar 6.4.

\section{Dudukan Teleskop atau Mounting}

Selain sebagai tempat didudukannya teleskop, mounting juga berfungsi sebagai penggerak otomatis agar dapat mengikuti gerakan objek yang diamati. Mounting yang digunakan ISRN UHAMKA sudah berbasis computerized atau terdapat sistem komputer yang berjalan secara otomatis menggerakan teleskop untuk mengikuti gerakan Bulan terhadap Bumi. Ada beberapa pengaturan yang harus 
AL-MARSHAD: JURNAL ASTRONOMI ISLAM DAN ILMU-ILMU BERKAITAN

ISSN 2442-5729 (print) || ISSN 2598-2559 (online), http://jurnal.umsu.ac.id/index.php/almarshad DOI: https://doi.org/10.30596/jam.v4i1.1931

Published June 2018

dilakukan oleh pengamatan sebelum melakukan pengamatan, diantaranya: (1) mengatur orientasi posisi di muka Bumi,(2) waktu dan tanggal, dan (3) memilih objek yang dipilih untuk diamati. Mounting yang digunakan leh ISRN UHAMKA adalah iOptron CEM60, karakteristik mounting seperti tabel 3 dan pada gambar 7.

Tabel 3. Karakteristik Mounting iOptron CEM60 ${ }^{10}$

\begin{tabular}{|l|l|}
\hline Mount & $\begin{array}{l}\text { Center-balanced } \\
\text { Equatorial Mount (CEM) }\end{array}$ \\
\hline Payload & $\begin{array}{l}60 \mathrm{lb}(27.2 \mathrm{~kg}), \text { exclude } \\
\text { counterweight* }\end{array}$ \\
\hline Mount weight & $27 \mathrm{lb}(12.3 \mathrm{~kg})$ \\
\hline $\begin{array}{l}\text { Payload/Mount } \\
\text { weight ratio }\end{array}$ & $2.22: 1$ \\
\hline Material & $\begin{array}{l}\text { All metal (except GPS } \\
\text { cover) }\end{array}$ \\
\hline $\begin{array}{l}\text { Latitude } \\
\text { adjustment } \\
\text { range }\end{array}$ & $0^{\circ} \sim 70^{\circ}$ \\
\hline $\begin{array}{l}\text { Azimuth } \\
\text { adjustment } \\
\text { range }\end{array}$ & $\pm 8^{\circ}$ \\
\hline $\begin{array}{l}\text { Right Ascension } \\
\text { worm wheel }\end{array}$ & $\begin{array}{l}\Phi 146 \mathrm{~mm}, 288 \text { tooth } \\
\text { aluminum }\end{array}$ \\
\hline $\begin{array}{l}\text { Declination } \\
\text { worm wheel }\end{array}$ & $\begin{array}{l}\Phi 146 \mathrm{~mm}, 288 \text { tooth } \\
\text { aluminum }\end{array}$ \\
\hline PEC & PPEC \\
\hline PE & $< \pm 5$ arcsec p-p \\
\hline $\begin{array}{l}\text { Counterweight } \\
\text { shaft }\end{array}$ & $\begin{array}{l}\Phi 28 \mathrm{x} 450 \mathrm{~mm} \text { Stainless } \\
\text { Steel }\end{array}$ \\
\hline
\end{tabular}

\begin{tabular}{|c|c|}
\hline ounterweight & $21 \mathrm{lb}(9.5 \mathrm{~kg})$ \\
\hline Mount base size & $\Phi 150 \mathrm{~mm}$ \\
\hline Motor drive & Stepper motor \\
\hline Resolution & 0.06 arc seconds \\
\hline Slew speed & $\begin{array}{l}1 \times, 2 \times, 8 \times, 16 \times, 64 \times, 128 \times, 2 \\
56 \times, 512 \times, \operatorname{MAX}\left(\sim 3.75^{\circ} / \mathrm{s}\right. \\
\text { ec })\end{array}$ \\
\hline $\begin{array}{l}\text { Power } \\
\text { consumption }\end{array}$ & $\begin{array}{l}0.6 \mathrm{~A}(\text { Tracking }), 1.1 \mathrm{~A}(\mathrm{GO} \\
\mathrm{TO})\end{array}$ \\
\hline $\begin{array}{l}\text { Power } \\
\text { requirement }\end{array}$ & $12 \mathrm{~V} \mathrm{DC} 2 \mathrm{~A}$ \\
\hline AC adapter & 100V 240V (included) \\
\hline Polar Scope & $\begin{array}{l}\text { AccuAlign } \mathrm{TM} \text { dark field } \\
\text { illuminated, } 2 \text { arc min }\end{array}$ \\
\hline Level indicator & Level bubble \\
\hline Dovetail saddle & $\begin{array}{l}\text { 8" Losmandy/Vixen dual } \\
\text { saddle }\end{array}$ \\
\hline Hand Controller & $\begin{array}{l}\text { Go2Nova® } 8407+ \\
359,000 \text { objects database, } \\
\text { star recognition }\end{array}$ \\
\hline $\begin{array}{l}\text { Meridian } \\
\text { treatment }\end{array}$ & $\begin{array}{l}\text { Stop }\left(0-15^{\circ} \text { pass }\right) \text {, auto } \\
\text { flip }\end{array}$ \\
\hline GPS & Internal 32-channel GPS \\
\hline Autoguide port & ST-4 \\
\hline $\begin{array}{l}\text { Communication } \\
\text { port }\end{array}$ & Serial port \\
\hline $\begin{array}{l}\text { PC computer } \\
\text { control }\end{array}$ & Yes (ASCOM) \\
\hline $\begin{array}{l}\text { Cable } \\
\text { management }\end{array}$ & $\begin{array}{l}\text { 4X USB, 2X DC12V } \\
\text { (MAX 5A), 6P6C }\end{array}$ \\
\hline $\begin{array}{l}\text { Operation } \\
\text { temperature }\end{array}$ & $-20^{\circ} \mathrm{C} \sim+45^{\circ} \mathrm{C}$ \\
\hline Tripod & $\begin{array}{l}\text { Optional } 2 \text { "tripod } \\
\text { Stainless Steel( } 8 \mathrm{~kg}) / \text { Pier } \\
(10 \mathrm{~kg})\end{array}$ \\
\hline Warranty & Two year limited \\
\hline
\end{tabular}




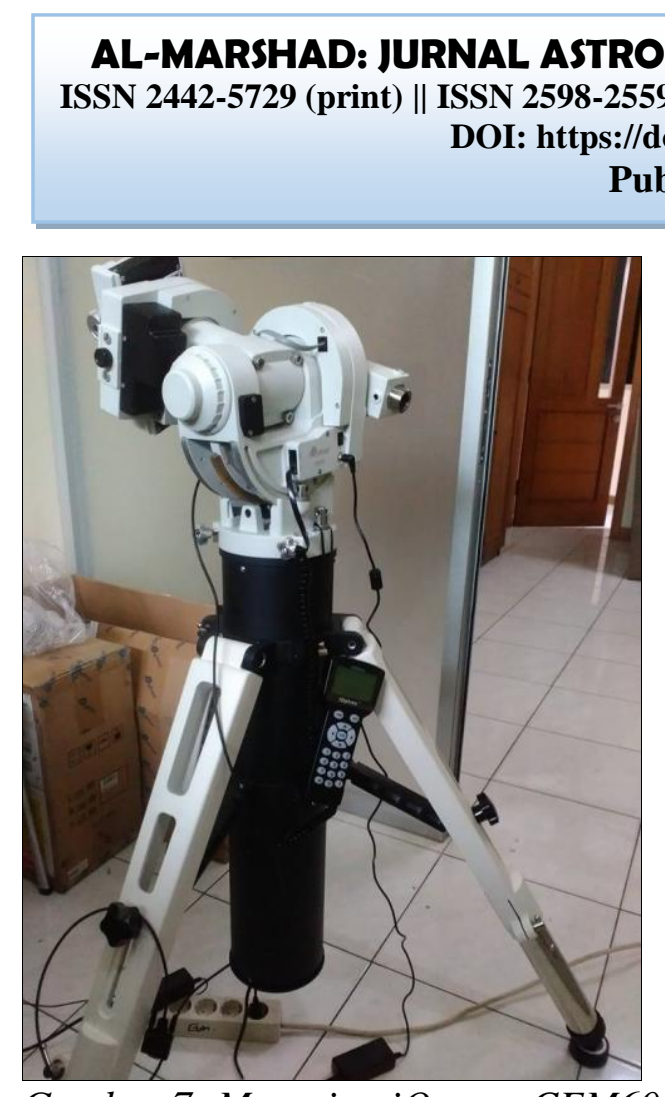

Gambar 7: Mounting iOptron CEM60

\section{Penapis Cahaya (Baffle)}

Mengamati hilal, apalagi untuk kontestasi pemecahan rekor jarak elongasi melahirkan masalah tersendiri yaitu kuatnya cahaya Matahari karena jaraknya yang relatif dekat. Untuk mengatasi masalah tersebut, ISRN UHAMKA menambahkan instrumen tambahan berupa penapis cahaya (baffle) yang akan menapis sumbersumber cahaya lainnya se[erti cahaya Matahari dan cahay akibat scattering. Untuk penapis cahaya, ada dua bentuk penapis yang digunakan ISRN UHAMKA, yang pertama bentuk yang sangat sederhana berupa kertas hitam yang digulung, seperti pada gambar 8 . Kedua, penapis yang dibuat sendiri dengan memperhatikan fungsi dan ergonomis, penapis cahaya yang dibuat seperti pada gambar 9. Fungsi penapis cahaya selain untuk menapis sumbersumber cahaya yang menngganggu, juga dapat meningkatkan kotras $13 \%{ }^{11}$.

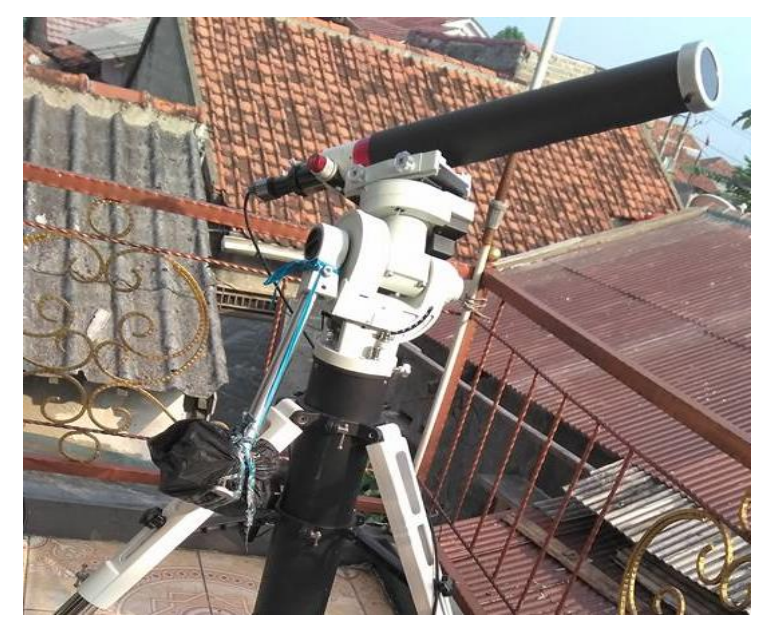

Gambar 8: Penapis sederhana dengan kertas hitam

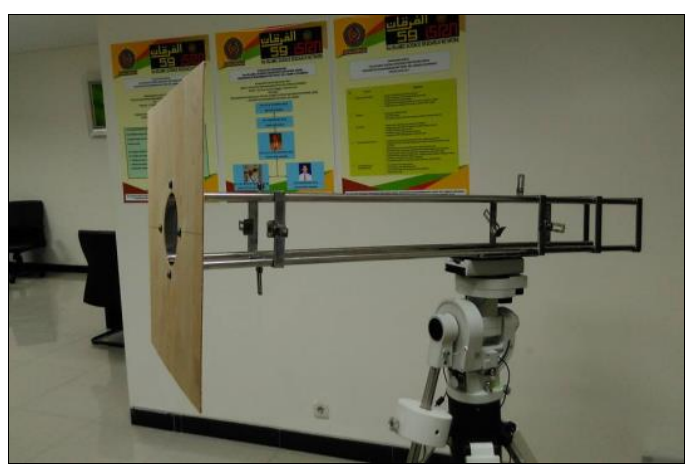

Gambar 9: Penapis cahaya ISRN UHAMKA

\section{Perangkat Lunas Kontrol Kamera}

Kamera yang digunakan sebagai detektor merupakan kamera digital,

11 Adi Damanhuri, Desain Sistem Pengamatan Sabit Bulan di Siang Hari, (Jakarta: SEMNASTEK, 2015), h.18. 


\section{AL-MARSHAD: JURNAL ASTRONOMI ISLAM DAN ILMU-ILMU BERKAITAN}

ISSN 2442-5729 (print) || ISSN 2598-2559 (online), http://jurnal.umsu.ac.id/index.php/almarshad DOI: https://doi.org/10.30596/jam.v4i1.1931

Published June 2018

maka dibutuhkan perangkat lunak untuk mengontrol kerja kamera detektor tersebut. Perangkat lunak yang dibangun menggunakan bahasa pemrograman $\mathrm{C \#}$, mengingat System Development Kit (SDK) yang diberikan oleh produsen kamera CCD Skyris 274 M menyediakan SDK untuk bahasa C\#. Pada perangkat lunak yanng dibangun sudah memuat fungsi capture atau pengambilan data atau citra, dan fungsi modifikasi citra berupa enhancement. Tampilan perangkat lunak kontrol kamera yang dibangun diberi nama Aplikasi Kontrol Kamera ISRN UHAMKA, tampilannya seperti pada gambar 10.

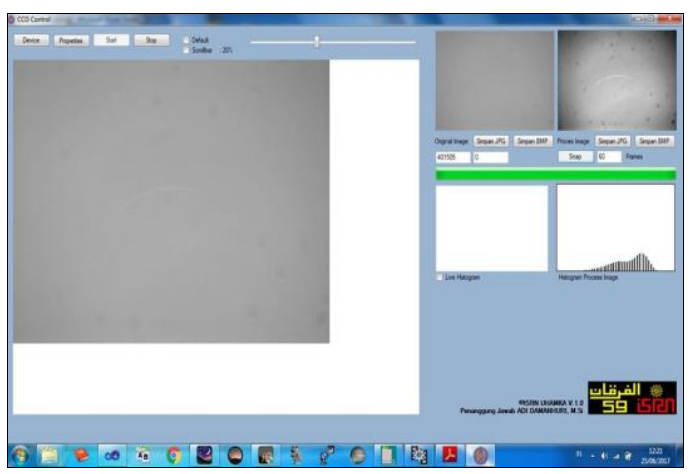

Gambar 10: Tampilan Perangkat Lunak Kontrol Kamera ISRN UHAMKA

\section{Hasil Pengamatan}

Dengan sistem pengamatan hilal

ISRN UHAMKA yang terdiri dari berbagai instrumen dengan berbasis teknologi, pengamatan hilal yang dilakukan ISRN UHAMKA makin mudah dilakukan. Konfigurasi semua instrumen terlihat seperti pada gambar 11.

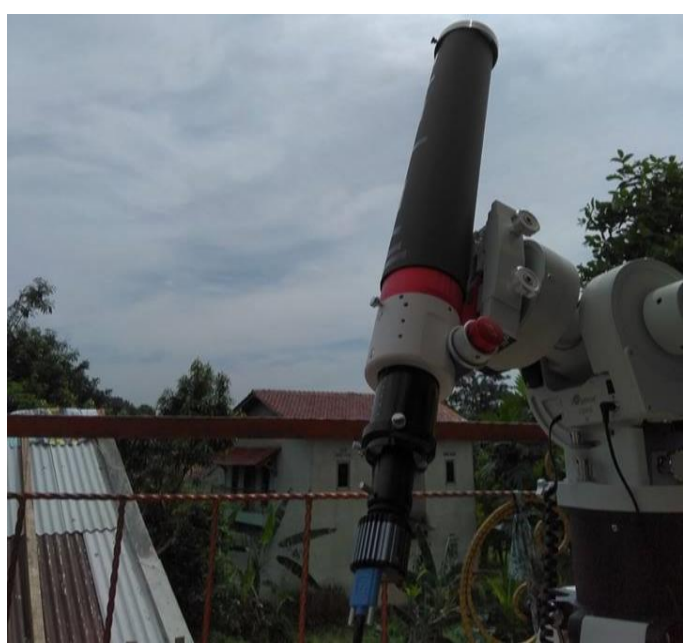

Gambar 11: Sistem Pengamatan Hilal ISRN UHAMKA

Sistem pengamatan hilal ISRN UHAMKA, telah diaplikasikan untuk mengamati hilal pada

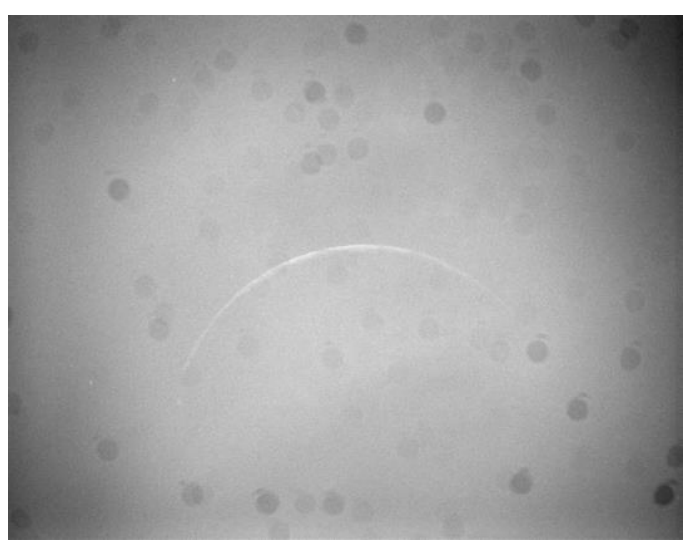

Gambar 12: Hasil pengamatan hilal ISRN UHAMKA pada 25 Juni 2017, Pkl. 12:20:20 (UT+7)

\section{F. Penutup}

Pengamatan hilal menjadi sangat penting mengingat sebagian besar umat 
AL-MARSHAD: JURNAL ASTRONOMI ISLAM DAN ILMU-ILMU BERKAITAN

ISSN 2442-5729 (print) || ISSN 2598-2559 (online), http://jurnal.umsu.ac.id/index.php/almarshad DOI: https://doi.org/10.30596/jam.v4i1.1931

Published June 2018

Islam di Indonesia melakukan pengamatan hilal untuk menentukan awal bulan hijriah, selain itu juga ada dimensi kontestasi pada pemecahan rekor hilal dengan jarak elongasi terdekat dengan Matahari. Untuk baiknya pengamatan hilal, dengan melibatkan dan menerapkan teknologi pada sistem pengamatan menjadikan proses pengamatan hilal menjadi mudah dan lebih sederhana. Sistem pengamatan hilal ISRN UHAMKA menjadi satu diantara banyak sistem pengamatan yang ada. Dengan kemudahan sistem pengamatan ini, berharap agar masyarakat penggiat pengamatan hilal dapat mengadopsi minimal menjadi referensi tambahan.

\section{Daftar Pustaka}

Adi Damanhuri. (2015). Desain Sistem Pengamatan Sabit Bulan di Siang Hari, Jakarta: SEMNASTEK.

Badan Pusat Statistik. (2010). Hasil Sensus Penduduk 2010: Kewarganegaraan, Suku Bangsa, Agama, dan Bahasa Sehari-Hari Penduduk Indonesia, Jakarta: Badan Pusat Statistik.

Dhani Herdiwijaya, Mitra Djamal, M., Gunawan, Mexsida, Z.A., Deni Mandey, Wijaya,R.R. (2010). Developing Telescope Baffle For
Increasing Contrast Of The Very Young Lunar Crescent Visibility. ( Bandung: Proceedings of the Thrid International Conference on Mathematical and Natural Sciense.

$$
\begin{aligned}
& \text { Doggett, L.E., Schaeffer, B.E. (1994). } \\
& \text { Lunar Crescent Visibility, } \\
& \text { ICARUS. }
\end{aligned}
$$

Http://williamoptics.com/20thedition/zenithstar-71-doublet-ed, diakses pada 15 Mei 2018, Pkl. 07:13:23 (UT+7)

\section{Ioptron CEM60 Center-Balanced Equatorial Mount: Instruction Manual, 2017.}

